Journal homepage: https://ejurnal.poltekkes-tjk.ac.id/index.php/JKM/index

\title{
Pengaruh Latihan Otot Perut terhadap Diastasis Recti Abdominalis Muscle pada Ibu Pasca Melahirkan Normal
}

The Effect of Abdominal Muscle Training on Diastasis Recti in Normal Delivery

\author{
Marti Rustanti ${ }^{1 凶}$, Saifudin Zuhri ${ }^{2}$ \\ ${ }^{1}$ Jurusan Fisioterapi Poltekkes Kemenkes Surakarta, Indonesia \\ ${ }^{\bowtie}$ Corresponding author e-mail: rustantiroesyid@gmail.com, Alamat: Jln Kapten Adisumarmo, Colomadu, \\ Karanganyar, Surakarta, Indonesia 57173
}

Article History:
Received Maret 2020
Revised Mei 2020
Accepted Juni 2020

Keywords:

Diastasis recti abdominal muscle; abdominal muscle exercises; postpartum mothers

\section{Kata kunci:}

Diastasis recti abdominal muscle; latihan otot perut; ibu pasca melahirkan

\begin{abstract}
s
Background: As a result of pregnancy will cause diastasis Recti Abdominal Muscle (DRAM) or a gap that is formed due to the separation of the rectus abdominals muscle during uterine enlargement and after childbirth. DRAM can affect the emergence of various cases such as low back pain, urinary incontinence, pelvic instability so that early treatment is needed. Purpose: This research is to find out the benefits of abdominal exercises against DRAM. Methods: Quasi-experimental research design with two groups pre and post-test design. The subject of the study was the postnatal vaginal delivery mothers who were divided into two groups randomly. The treatment group was given abdominal exercise for 4 weeks. Data were analyzed using the chisquare test used to test the measurement results. Results: There was a significant difference in effect between the treatment group and the control group $(\mathrm{p}=0.009$; $\mathrm{POR}=0,714$; CI 95\%: 0,545-0,936). Abdominal exercises contribute $41 \%$ to the closure of DRAM. Conclusion: Abdominal exercises (transversus abdominis) can prevent the incidence of DRAM in mothers after childbirth. Mothers after giving birth need to do the exercise independently or be guided by health workers.
\end{abstract}

\begin{abstract}
Abstrak
Latar Belakang: Akibat kehamilan akan menimbulkan Diastasis Recti Abdominal Muscle (DRAM) atau celah yang terbentuk oleh karena terpisahnya otot rectus abdominalis selama pembesaran rahim dan dan setelah melahirkan. DRAM dapat berpengaruh terhadap timbulnya berbagai kasus seperti nyeri punggung bawah, incontinensia urin, instabilitas panggul, sehingga perlu terapi dini. Tujuan: Penelitian ini untuk mengetahui manfaat latihan otot perut terhadap DRAM. Metode: Desain penelitian quasi eksperimen dengan two group pre and post test design. Subjek penelitian adalah ibu pasca melahirkan normal yang terbagi menjadi dua kelompok secara acak. Kelompok perlakuan diberikan latihan otot perut selama 4 minggu. Data dianalisis dengan menggunakan uji chi-square digunakan untuk menguji hasil pengukuran. Hasil: Terdapat perbedaan pengaruh antara kelompok perlakuan dengan kelompok kontrol secara bermakna ( $\mathrm{p}=0,009$; POR=0,714; CI 95\%: 0,545-0,936). Latihan otot perut berkontribusi sebesar $41 \%$ dalam penutupan DRAM. Simpulan: Latihan otot perut (transversus abdominis) mampu mencegah insiden DRAM pada ibu pasca melahirkan. Ibu setelah melahirkan perlu melakukan latihan dengan mandiri atau dibimbing oleh tenaga kesehatan.
\end{abstract}

Copyright (C 2020 Jurnal Kesehatan Metro Sai Wawai All rights reserved.

\section{Pendahuluan}

Peningkatan kesehatan ibu adalah merupakan salah satu sasaran dari tujuan pembangunan millennium (Millennium Development Goals) yang berlanjut menjadi tujuan pembangunan berkelanjutan (Sustainable Development Goals). Salah satu masalah kesehatan ibu yang banyak dijumpai adalah diastasis recti abdominis muscle (DRAM). DRAM adalah gangguan berupa pemisahan garis tengah dari dua otot rectus abdominis disepanjang linea alba. Penguluran otot perut menjadi penyebab terjadinya DRAM yang dipengaruhi oleh usia dan status gizi (berat badan) (Gruszczyńska \& 
Truszczyńska-Baszak, 2018). Selama kehamilan dengan bertambah besar rahim semakin mempengaruhi bentuk perut dan posisi tulang belakang lumbar, sehingga terjadi peningkatan jarak antara otot-otot perut dan perubahan sudut otot perut. Secara fungsional, mengurangi kekuatan, dan terutama terjadi pada otototot rektus abdominis. Akibatnya terjadi peregangan dan flacciditas linea alba, sehingga terjadi pembesaran jarak antara batas medial otot-otot dan terjadi DRAM (Michalska, Rokita, Wolder, Pogorzelska \& Kaczmarczyk, 2018).

DRAM sering ditemukan pada wanita hamil dan pasca melahirkan. Prevalensi DRAM berbedabeda pada masing-masing usia kehamilan. Pada kehamilan 21 minggu sebesar 33,1\% dan pada 6 minggu pasca persalinan sebesar $60 \%$, pada 6 bulan pasca persalinan sebesar $45,4 \%$ dan pada 12 bulan pasca persalinan sebesar 32,6\% (Sperstad, Tennfjord, Hilde, Ellström-Engh, \& Bo, 2016). DRAM ini diukur dengan menggunakan alat ukur yang paling sederhana dengan menggunakan jari tangan maupun alat ukur yang paling modern yang menggunakan Ultrasound Imaging (USI) (Keshwani, Hills \& Lean, 2016).

DRAM yang belum menutup setelah melahirkan, berpengaruh terhadap munculnya berbagai kasus seperti nyeri punggung bawah, instabilitas panggul, inkontinensia urin dan inkontensia feces, sindrom vestibulitis vulva, interstitial, sistitis atau herniasi diskus (Gruszczyńska \& TruszczyńskaBaszak, 2018). Berdasarkan risiko-risiko yang telah diuraikan di atas, sebaiknya DRAM harus segera diatasi. Penanganan DRAM pada umumnya dilakukan oleh Fisioterapi, apabila belum tuntas masalahnya biasanya ditindaklanjuti dengan penangan secara operasi (Jessen, Oberg \& Rosenberg, 2019).

Beberapa penelitian telah dilakukan untuk mengatasi DRAM, diantaranya adalah penggunaan rangsangan elektris maupun latihan aktif yang melibatkan otot. Penggunaan stimulasi elektris hasilnya tidak lebih baik apabila dibandingkan dengan latihan (Kamel \& Yousif, 2017). Pemberian latihan banyak dilakukan untuk pengembalian jarak DRAM, tetapi yang dituju tidak hanya satu otot. (Michalska, Rokita, Wolder, Pogorzelska \& Kaczmarczyk, 2018). Ada penelitian yang berfokus melatih otot perut, ada penelitian yang berfokus pada latihan otot perut dan otot dasar panggul (Thabet \& Alshehri, 2019) dan ada juga penelitian fokus melatih otot dasar panggul. Sebagian besar latihan yang ditujukan pada otot bertujuan untuk memperbaiki nilai otot atau meningkatkan kekuatan otot (Benyamin, Van de Water \& Peiris, 2014). Bentuk latihan otot perut maupun latihan otot perut dikombinasi otot dasar panggul, sudah terbukti dapat memperbaiki DRAM yang ada, sedangkan penelitian dengan fokus latihan otot dasar panggul terbukti tidak efektif memperbaiki DRAM (Gluppe, Engh, \& Bo, 2020).

Penelitian ini membedakan dengan penelitian sebelumnya dengan melakukan penelitian menggunakan intervensi yang lebih simpel yang masih jarang diteliti. Namun, hasil penelitian diharapkan yang akan datang dapat dilakukan mandiri oleh ibu pasca melahirkan, yaitu memberikan latihan yang ditujukan pada otot perut, khususnya otot transversus abdominis. Penelitian ini bertujuan membuktikan latihan otot perut dapat memberikan pengaruh terhadap penurunan inciden DRAM.

\section{Metode}

Eksperimental semu (Quasi experimental) merupakan desain penelitian ini, karena kontrol terhadap variabel penelitian terbatas atau kurang ketat, mengingat peneliti tidak melakukan pembatasan khusus kepada subjek penelitian dengan jenis two group pre and post test design (Murti, 2016). Penelitian dilaksanakan mulai pertengahan bulan Juni sampai September akhir 2019 di Bidan Praktik Mandiri di kecamatan Ngemplak kabupaten Boyolali. Subjek penelitian yang diambil memenuhi kriteria inklusi berupa, perempuan usia kurang dari 40 tahun, pasca melahirkan normal antara 1 hari sampai dengan 1 minggu, tidak mengalami masalah kesehatan, bersedia berparsipasi sampai selesai penelitian. 
Sedangkan, kriteria ekslusi jika mempunyai keluhan yang berhubungan dengan penyakit jantung. Kriteria drop out pada penelitian ini adalah subjek tidak mengikuti proses intervensi sampai selesai atau tidak bisa dilakukan pengukuran akhir setelah intervensi.

Pengukuran dilakukan dengan menggunakan alat ukur DRAM berupa jari tangan. Untuk menjaga reliabilitas hasil ukur pengukuran dilakukan oleh satu orang pengukur. Hasil pengukuran ini bisa berupa jumlah jari atau bisa juga dikonversikan dalam satuan senti meter dengan cara melakukan dahulu pengukuran lebar jari kedua, ketiga dan ke empat dari pengukur. Prosedur intervensi dilakukan setelah diperoleh subyek penelitian yang memenuhi kriteria inkluasi dan eksklusi. Semua subjek penelitian secara acak dibagi menjadi dua kelompok. Pada kelompok perlakuan diberikan latihan kontraksi otot perut yaitu otot transversus abdominis dengan 3 macam posisi yaitu posisi berbaring, duduk dan berdiri. Dosis kontraksi 10 hitungan, dilakukan 8 kali pengulangan setiap latihan. Latihan dilakukan setiap hari sekali selama 4 minggu. Pada kelompok kontrol tidak diberikan perlakuan secara khusus, tetapi subjek diberikan anjuran mobilisasi dini dan melakukan aktivitas sehari-hari setelah melahirkan sesuai anjuran tenaga kesehatan atau Bidan. Observasi dengan melakukan pengukuran celah linea alba pada rectus abdominalis muscle. Pengukuran dilakukan sebelum intervensi dan 4 minggu setelah intervensi.

Data dilakukan analisis statistik deskriptif digunakan untuk menganalisis karakteristik subjek, sedangkan analisis chi-square digunakan untuk menguji hasil pengukuran perbedaan pre dan post DRAM, karena uji chi-square adalah uji hipotesis komparatif kategorik tidak berpasangan berdistribusi tidak normal (Dahlan, 2015). Penelitian dilakukan dengan mempertimbangkan etik penelitian setelah melalui proses pemberian izin penelitian oleh Politeknik Kesehatan Kemenkes Surakarta, tempat penelitian, dan informed consent dari subjek penelitian. Penelitian ini juga sudah mendapatkan ijin laik etik per tanggal 4 Februari 2019 dengan No LB.02.02/1.3/583/2019.

\section{Hasil}

\section{Karakteristik subyek penelitian}

Karakteristik subjek penelitian pada tabel 1 memperlihatkan usia produktif 20-35 tahun yang dominan baik pada kelompok perlakukan (86,36\%) dan kelompok kontrol $(95,23 \%)$. Sedangkan, karakterisrik subyek berdasarkan paritas yang terbanyak adalah paritas 2-3 anak pada kelompok perlakuan berjumlah $68,2 \%$ dan kelompok kontrol $71,4 \%$.

Tabel 1.

Karakteristik subjek penelitian

\begin{tabular}{lll}
\hline Karakteristik & Kelompok Perlakuan $(\mathrm{n}=22)$ & Kelompok Kontrol $(\mathrm{n}=21)$ \\
\hline Usia & & \\
$\quad<20$ th & $1(4,54 \%)$ & $0(0,0 \%)$ \\
$20-35$ th & $19(86,36 \%)$ & $20(95,23 \%)$ \\
$>35$ th & $2(9,09 \%)$ & $1(4,76 \%)$ \\
$\quad$ Mean usia (tahun) & 26,72 & 28,23 \\
Paritas & & \\
1 anak (Primipara) & $5(22,7 \%)$ & $6(28,6 \%)$ \\
$2-3$ anak & $15(68,2 \%)$ & $15(71,4 \%)$ \\
$>3$ anak (Multipara) & $2(9,1 \%)$ & $0(0,0 \%)$ \\
\hline
\end{tabular}

\section{Hasil Pengukuran DRAM}

Hasil pengukuran DRAM pada tabel 2, diperoleh hasil pada minggu ke 4 seluruh subjek (100\%) pada kelompok perlakuan memberikan efek penutupan DRAM, sedangkan pada kelompok kontrol baru $71,4 \%$. Oleh karena data yang dihasilkan berupa data kategorik tidak berpasangan dan hasil ukur akhir 
pada kelompok perlakuan mendapatkan data berupa angka 0 semua maka analisis data menggunakan uji chi-suare (Dahlan, 2015).

Tabel 2.

Distribusi Frekuensi hasil pengukuran waktu penutupan DRAM

\begin{tabular}{cllll}
\hline \multirow{2}{*}{ Minggu } & \multicolumn{2}{c}{ Kelompok Perlakuan } & \multicolumn{2}{c}{ Kelompok Kontrol } \\
& F & $\mathbf{\%}$ & $\mathbf{F}$ & $\mathbf{\%}$ \\
\hline Ke-1 & 0 & $0 \%$ & 0 & $0 \%$ \\
Ke-2 & 7 & 31,8 & 0 & $0 \%$ \\
Ke-3 & 7 & 31,8 & 15 & $0 \%$ \\
Ke-4 & 8 & 36,4 & 15 & 71,4 \\
Jumlah & 22 & 100 & & 71,4 \\
\hline
\end{tabular}

Hasil pengukuran DRAM pada tabel 3, sebelum intervensi selama 4 minggu pada kelompok perlakuan yang terbanyak (45,5\%) dengan DRAM 2 jari, sedangkan pada kelompok kontrol yang terbanyak 52,4\% dengan DRAM sebesar 2 jari. DRAM setelah intervensi pada kelompok perlakuan $100 \%$ telah menutup, sedangkan pada kelompok kontrol masih terdapat $28,6 \%$ yang belum menutup atau DRAM 1 jari. Secara keseluruhan DRAM yang menutup pada ibu melahirkan normal terdapat $86,0 \%$ dan selebihnya $28,6 \%$ belum menutup terjadi pada kelompok kontrol.

Tabel 3.

Hasil pengukuran DRAM sebelum dan sesudah intervensi pada kelompok perlakuan dan kelompok kontrol

\begin{tabular}{lcccccccc}
\hline \multirow{2}{*}{ Kelompok } & \multicolumn{3}{c}{$\begin{array}{c}\text { Lebar DRAM Awal } \\
\text { f (\%) }\end{array}$} & \multicolumn{3}{c}{$\begin{array}{c}\text { Lebar DRAM Akhir } \\
\text { f(\%) }\end{array}$} \\
\cline { 2 - 9 } & $\mathbf{0}$ jari & $\mathbf{1}$ jari & $\mathbf{2}$ jari & $>$ 3 jari & $\mathbf{0}$ jari & 1 jari & 2 jari & $>$ 3 jari \\
\hline Perlakuan $(\mathrm{n}=22)$ & 0 & 0 & 10 & 12 & 22 & 0 & 0 & 0 \\
\multirow{3}{*}{ Kontrol $(\mathrm{n}=21)$} & $(0,0 \%)$ & $(0,0 \%)$ & $(45,5 \%)$ & $(5,5 \%)$ & $(100 \%)$ & $(0,0 \%)$ & $(0,0 \%)$ & $(0,0 \%)$ \\
& 0 & 1 & 11 & 9 & 15 & 6 & 0 & 0 \\
\multirow{3}{*}{ Jumlah total } & $(0,0 \%)$ & $(4,8 \%)$ & $(52,4)$ & $(42,9 \%)$ & $(71,4 \%)$ & $(28,6 \%)$ & $(0,0 \%)$ & $(0,0 \%)$ \\
& 0 & 1 & 21 & 19 & 37 & 6 & 0 & 0 \\
& $(0,0 \%)$ & $(2,3 \%)$ & $(48,8 \%)$ & $(44,1 \%)$ & $(86,0 \%)$ & $(13,8 \%)$ & $(0,0 \%)$ & $(0,0 \%)$ \\
\hline
\end{tabular}

\section{Pengaruh latihan otot perut terhadap DRAM pada ibu melahirkan normal}

Tabel 4 merupakanhasil uji statistik pengukuran setelah intervensi antara kelompok perlakuan dan kelompok kontrol menggunakan chi square menunjukkan perbedaan pengaruh latihan otot perut terhadap DRAM secara bermakna ( $p=0,009$; CI 95\%: 0,545-0,936). Hasil uji statistik juga diperoleh bahwa penambahan latihan otot perut berkontribusi sebesar $41 \%$ terhadap percepatan penutupan DRAM.

Tabel 4.

Hasil analisis pengaruh latihan otot perut terhadap DRAM pada ibu melahirkan normal

\begin{tabular}{|c|c|c|c|c|c|}
\hline \multirow[b]{2}{*}{ DRAM Setelah Perlakuan* } & \multicolumn{2}{|l|}{ Kelompok } & \multirow{2}{*}{$\begin{array}{l}\text { Jumlah } \\
\text { Total }\end{array}$} & \multirow[b]{2}{*}{ POR (CI 95\%) } & \multirow[b]{2}{*}{ P-value } \\
\hline & $\begin{array}{l}\text { Perlakuan } \\
\text { f }(\%)\end{array}$ & $\begin{array}{l}\text { Kontrol } \\
\text { f }(\%)\end{array}$ & & & \\
\hline Tertutup & $22(100 \%)$ & $15(71,4 \%)$ & $86,0 \%$ & \multirow{3}{*}{$\begin{array}{l}0,714 \\
(0,545-0,936)\end{array}$} & \multirow{3}{*}{0,009} \\
\hline Tidak Terutup ( 1 jari) & $0(0,0 \%)$ & $6(28,6 \%)$ & $14,0 \%$ & & \\
\hline Jumlah & $22(100 \%)$ & $21(100 \%)$ & $100 \%$ & & \\
\hline
\end{tabular}

*Directional Measures sebesar 0,412 atau 41\%.

Keterangan: $\mathrm{f}=$ frekuensi, $C I=$ confindent interval 


\section{Pembahasan}

Perubahan otot abdomen selama kehamilan berupa pemisahan otot dinding abdomen bagian depan (anterior) memungkinkan terjadi sampai ibu pasca melahirkan atau disebut diastasis rectus abdominis. (Mota, Mascoal, Carita, \& Bo, 2015). Studi ini untuk menguji efek latihan otot perut terhadap DRAM. Terbukti berdasarkan hasil analisis penelitian menunjukkan bahwa latihan otot perut pada ibu pasca melahirkan normal selama 4 minggu mempunyai efek dapat mempercepat penutupan DRAM pada ibu melahirkan normal secara bermakna. Selanjutnya penelitian menemukan bahwa latihan otot perut dapat menyumbang sebesar $41 \%$ dalam mempercepat penutupan DRAM.

Diastasis recti abdominis muscle (DRAM) sebagai pemisahan otot rectus abdominis di linea alba yang menghubungkan dua bagian otot ini (Gruszczyńska \& Truszczyńska-Baszak, 2018). Saat kehamilan, perubahan geometri otot perut masih mempertahankan fungsinya. Namun, bertambah besar rahim selama kehamilan semakin mempengaruhi bentuk perut dan posisi tulang belakang lumbar (memperdalam lumbosis lumbar) yang menghasilkan peningkatan jarak antara pemasangan, yaitu perpanjangan otot-otot perut dan perubahan sudut otot perut. Secara fungsional, ini dimanifestasikan oleh pengurangan kekuatan, dan terutama mempengaruhi otot-otot rektus abdominis. Hal ini menyebabkan peregangan dan flacciditas linea alba yang dapat menyebabkan pembesaran jarak antara batas medial otot-otot, sehingga memungkinkan terjadi DRAM (Michalska, Rokita, Wolder, Pogorzelska \& Kaczmarczyk, 2018).

Kondisi DRAM terjadi terutama pada wanita hamil (biasanya pada trimester ketiga. Kondisi ini dialami oleh $100 \%$ wanita hamil 35 minggu. Ini dapat berlanjut selama 6 minggu postpartum pada 50\% $-60 \%$ wanita atau bahkan selama 6 bulan postpartum pada $39 \%-45 \%$ wanita. DRAM tidak menimbulkan gejala nyeri. Nyeri dapat terjadi hanya ketika efek dari kondisi ini muncul. Jaringan perut, perineum dan panggul diregangkan selama kehamilan. Recti abdominalis tidak selalu kembali ke keadaan semula setelah melahirkan. Konsekuensi dari gerakan perut yang bergeser ke depan karena DRAM dapat mengakibatkan perubahan statika tubuh dengan pusat gravitasi bergerak 2 sentimeter ke depan dan mencegah otot-otot tersebut mengerahkan tekanan berlebihan pada tulang belakang lumbar. Hal ini juga terkait dengan mempertahankan postur tubuh yang tepat dan mencegah anteversi panggul yang berlebihan dan lordosis lumbar. Sehingga, terjadi gangguan fungsional otot perut dapat menyebabkan nyeri tulang belakang dan disfungsi dan komplikasi lain seperti hernia abdominal. Tonjolan di daerah garis median anterior abdomen yang dapat diamati pada individu dengan DRAM juga merupakan masalah estetika (Gruszczyńska \& Truszczyńska-Baszak, 2018).

Potensi terjadinya DRAM menjadi alasan dan pentingnya melakukan pencegaha atau terapi (Gruszczyńska \& Truszczyńska-Baszak, 2018). Latihan otot perut yang dilakukan secara rutin dan terus menerus berdampak pada peningkatan kinerja otot seperti elastisitas atau kemampuan mengulur dan memendek otot, kekuatan dan daya tahan otot. Peningkatan elastisitas otot perut, membantu menurunkan DRAM. Otot perut yang merupakan antagonis dari otot-otot punggung sekaligus sebagai stabilisator dari sendi-sendi vertebra. Kondisi otot perut yang baik, membantu meningkatkan stabilitas punggung yang berdampak menurunkan risiko nyeri punggung bawah.

Penelitian ini mendukung dengan hasil penelitian Kamel \& Yousif (2017) bahwa latihan otot perut merupakan faktor yang sangat penting dalam membantu penurunan DRAM. Penelitian tersebut subjek menjadi dua kelompok dimana kelompok pertama diberikan perlakuan berupa latihan otot perut ditambah neuromuskuler electrical stimulation, sedangkan kelompok kedua hanya diberikan latihan otot perut saja. Hasil penelitian mereka menunjukkan bahwa kedua kelompok penelitian mengalami penurunan DRAM secara bermakna. Kamel \& Yousif (2017) memberikan perlakuan latihan otot perut melibatkan otot transversus abdominis, obliqus internus dan otot rectus abdominis. Namun, penelitian ini hanya melibatkan latihan otot transversus abdominis. Adapun penelitian Thabet \& Alshehri (2019) 
yang membandingkan latihan core stability dikombinasikan latihan otot perut dengan latihan otot perut dalam menurunkan DRAM pada ibu pasca melahirkan dengan melibatkan dua kelompok intervensi dan kelompok kontrol yang masing-masing kelompok berjumlah 20 orang. Hasil penelitiannya menunjukkan bahwa kelompok perlakuan yang diberikan latihan otot perut ditambah latihan core stability, lebih baik dibandingkan dengan kelompok kontrol yang hanya diberikan latihan otot perut.

Sesuai dengan hasil penelitian Chiarello, Falzone, Mc Caslin, Patel \& Ulery (2005) Latihan otot perut khususnya transversus abdominis terbukti secara bermakna menurunkan insiden DRAM pada perempuan hamil. Mereka membandingkan kelompok ibu hamil yang diberikan latihan otot transversus abdominis dengan kelompok kontrol tanpa latihan otot perut yang hasilnya menunjukkan bahwa kelompok ibu hamil dengan latihan otot transversus abdominis menunjukkan penurunan DRAM lebih baik dibandingkan ibu hamil tanpa latihan. Persamaan penelitian ini dengan penelitian mereka adalah latihan otot perut ditujukan pada otot transversus abdominis, sedangkan perbedaannya adalah penelitian ini subjeknya ibu pasca melahirkan.

Penelitian-penelitian tersebut di atas menunjukkan bahwa latihan menjadi hal yang menentukan dalam penutupan DRAM, walaupun kebanyakan penelitian tidak menghitung berapa besar kontribusi latihan terhadap penutupan DRAM. Pada penelitian ini menganalisis bahwa latihan otot perut memberikan sumbangan sebesar $41 \%$ dalam penurunan DRAM. Penelitian ini juga menunjukkan bahwa ibu pasca melahirkan yang diberikan latihan otot perut selama 4 minggu mampu mencegah sebesar 0,7 kali terjadinya DRAM. Selain itu, intervensi pada kelompok perlakuan yang diberikan kepada subjek lebih simpel dan mudah dilakukan oleh responden, sehingga memungkinkan dilakukan pada ibu pasca melahirkan. Selain itu, penelitian belum mengendalikan faktor luar, seperti umur dan berat badan atau status gizi yang juga mempunyai efek terhadap DRAM pada ibu melahirkan normal. Namun, hasil penelitian ini aman jika ibu pasca untuk mempercepat menyatukan kembali otot-otot linea alba yang terpisah dengan latihan otot perut.

\section{Simpulan}

Latihan otot perut (tranversus abdominis) terus-menerus selama 4 minggu mampu memberikan pengaruh mencegah risiko terjadinya DRAM pada ibu pasca melahirkan. Ibu pasca melahirkan perlu melakukan latihan otot perut dengan dibimbing oleh tenaga kesehatan sedini mungkin, karena insiden DRAM akan menimbulkan efek lain, jika tidak mendapatkan terapi.

\section{Ucapan terima kasih}

Ucapan terima kasih yang pertama kami sampaikan kepada Poltekkes Kemenkes Surakarta yang telah menyediakan sumber dana untuk penelitian ini. Selanjutnya kepada partisipan dan Bidan yang telah terlibat langsung membantu penelitian ini.

\section{Referensi}

Benjamin, D. R., Van de Water, A. T. M., \& Peiris, C. L. (2014). Effects of exercise on diastasis of the rectus abdominis muscle in the antenatal and postnatal periods: a systematic review. Physiotherapy, 100(1), 1-8. DOI: https://doi.org/10.1016/j.physio.2013.08.005

Chiarello, C. M., Falzone, L. A., McCaslin, K. E., Patel, M. N., \& Ulery, K. R. (2005). The effects of an exercise program on diastasis recti abdominis in pregnant women. Journal of Women's Health Physical Therapy, 29(1), 11-16. Retreived from: https://insights.ovid.com/women-health-physicaltherapy/jwhpt/2005/29/010/effects-exercise-program-diastasis-recti-abdominis/3/01274882

Dahlan, M.S. (2015). Statistik untuk kedokteran dan kesehatan deskriptif, bivariat dan multivariat dilengkapi aplikasi menggunakan SPSS. Jakarta, Indonesia: Epidemiologi Indonesia. 
Gluppe, S. B., Engh, M. E., \& Bo, K. (2020). Immediate effect of abdominal and pelvic floor muscle exercises on interrecti distance in women with diastasis recti abdominis who were parous. Phys Ther. DOI: https://doi.org/10.1093/ptj/pzaa070

Gluppe, S. L., Hilde, G., Tennfjord, M. K., Engh, M. E., \& Bø, K. (2018). Effect of a postpartum training program on the prevalence of diastasis recti abdominis in postpartum primiparous women: A randomized controlled trial. Phys Ther, 98(4), 260-268. DOI: https://doi.org/10.1093/ptj/pzy008

Gruszczyńska, D., \& Truszczyńska-Baszak, A. (2018). Exercises for pregnant and postpartum women with diastasis recti abdominis - Literature review. Postepy Rehabilitacji, 32(3), 27-35. DOI: https://doi.org/10.5114/areh.2018.80967

Jessen, M. L., Öberg, S., \& Rosenberg, J. (2019). Treatment options for abdominal rectus diastasis. Frontiers in surgery, 6(65). DOI: https://doi.org/10.3389/fsurg.2019.00065

Kamel, D. M., \& Yousif, A. M. (2017). Neuromuscular electrical stimulation and strength recovery of postnatal diastasis recti abdominis muscles. Annals of rehabilitation medicine, 41(3), 465-474. DOI: https://doi.org/ 10.5535/arm.2017.41.3.465

Keshwani, N., Hills, N., \& McLean, L. (2016). Inter-rectus distance measurement using ultrasound imaging: does the rater matter? Physiotherapy Canada, 68(3), 223-229. DOI: https://doi.org/10.3138/ptc.2015-36

Michalska, A., Rokita, W., Wolder, D., Pogorzelska, J., \& Kaczmarczyk, K. (2018). Diastasis recti abdominis - A review of treatment methods. Ginekologia Polska, 89(2), 97-101. DOI: https://doi.org/10.5603/GP.a2018.0016

Mota, P. G. F. d., Pascoal, A. G. B. A., Carita, A. I. A. D., \& Bø, K. (2015). Prevalence and risk factors of diastasis recti abdominis from late pregnancy to 6 months postpartum, and relationship with lumbo-pelvic pain. Manual Therapy, 20(1), 200-205. DOI: https://doi.org/10.1016/j.math.2014.09.002

Murti, B. (2016). Prinsip dan metode riset epidemiologi. Solo: Prodi IKM, Program Pasca Sarjana UNS

Sperstad, J. B., Tennfjord, M. K., Hilde, G., Ellström-Engh, M., \& Bø, K. (2016). Diastasis recti abdominis during pregnancy and 12 months after childbirth: prevalence, risk factors and report of lumbopelvic pain. British Journal of Sports Medicine, 50(17), 1092-1096. DOI: https://doi.org/10.1136/bjsports-2016-096065

Thabet, A. A., \& Alshehri, M. A. (2019). Efficacy of deep core stability exercise program in postpartum women with diastasis recti abdominis: a randomised controlled trial. Journal of musculoskeletal \& neuronal interactions, 19(1), 62-68. Retreived from https:/www.ncbi.nlm.nih.gov/pmc/articles/PMC6454249/

Sitasi: Rustanti, M. \& Zuhri, S. (2020). Pengaruh latihan otot perut terhadap diastasis resti abdominalis muscle pada ibu pasca melahirkan normal. Jurnal Kesehatan Metro Sai Wawai. 13(1). 20-26. DOI: 10.26630/jkm.v13i1.2200

Hiperlink DOI: http://dx.doi.org/10.26630/jkm.v13i1.2200 